\title{
The Role of Cine Flow Magnetic Resonance Imaging in Patients with Chiari 0 Malformation
}

\author{
Kerem Mazhar OZSOY ${ }^{1}$, Kadir OKTAY ${ }^{2}$, Nuri Eralp CETINALP ${ }^{1}$, Yurdal GEZERCAN ${ }^{3}$, Tahsin ERMAN ${ }^{1}$ \\ ${ }^{1}$ Cukurova University, School of Medicine, Department of Neurosurgery, Adana, Turkey \\ ${ }^{2}$ Mehmet Akif Inan Training and Research Hospital, Neurosurgery Clinic, Sanliurfa, Turkey \\ ${ }^{3}$ Adana Numune Training and Research Hospital, Neurosurgery Clinic, Adana, Turkey
}

\section{ABSTRACT}

AIM: To define the role of phase-contrast cine magnetic resonance imaging (MRI) in deciding the therapeutic strategy and underlying pathophysiology resulting in syrinx formation in patients with Chiari type 0 malformation.

MATERIAL and METHODS: Seven patients who were admitted to our clinic with the diagnosis of Chiari 0 malformation from January 2005 to July 2016 were enrolled in the study. All patients underwent a detailed preoperative neurological examination. Entire neuroaxis MRI and phase-contrast cine MRI were obtained preoperatively and postoperatively.

RESULTS: Seven patients (5 female and 2 male) with Chiari type 0 malformation fulfilled the inclusion criteria. All of the patients had absent cine flow at the craniovertebral junction except two patients. These five patients underwent surgical interventions; suboccipital decompression and duraplasty. All of them showed both clinical and radiological improvement in the postoperative period.

CONCLUSION: Cine flow MRI appears to be a useful tool in the management of patients with Chiari 0 malformation. There was a good correlation between the clinical presentation and cine flow preoperatively, and between clinical improvement and cine flow in the postoperative period.

KEYWORDS: Chiari 0 malformation, Cine flow magnetic resonance imaging, Decompression, Duraplasty

\section{INTRODUCTION}

$\mathrm{T}$ The term "Chiari malformation" has been used to define conditions with ectopia of cerebellar tonsils below the level of the posterior edge of the foramen magnum for several decades. Since the late 1990s, the "Chiari type 0 malformation" is defined as syringomyelia without tonsillar herniation that responds to posterior fossa decompression (2325). The increasing awareness of this malformation has led to widespread use of magnetic resonance imaging (MRI). The pathophysiology resulting in syrinx formation in this group of patients is poorly understood and there is no consensus on the management of the patients. The responses to surgery suggest that a "Chiari-like" pathophysiology may be present in the absence of tonsillar herniation.
Phase-contrast cine flow $\mathrm{MRI}$ is a non-invasive method of studying cerebrospinal fluid (CSF) circulation in the brain and the craniocervical junction and also enables understanding the pathophysiology of the Chiari malformation. All the theories relating to the cause of Chiari type 0 malformation with an associated syrinx implicate abnormal CSF flow.

In the present study, we investigated the role of phase-contrast cine MRI in deciding the therapeutic strategy and the underlying pathophysiology resulting in syrinx formation in patients with Chiari type 0 malformation.

\section{MATERIAL and METHODS}

The medical records of the patients who were admitted to our clinic with the diagnosis of Chiari 0 malformation from 
January 2005 to July 2016 were reviewed. Seven patients (5 female and 2 male) fulfilled the inclusion criteria, which included Chiari type 0 malformation (cervical syringomyelia without cerebellar tonsils ectopia) without other causes of a syrinx. Five cases were operated, and suboccipital decompression and duraplasty were performed. All patients underwent entire neuroaxis MRI (GE 1.5T) with or without contrast enhancement (Figure 1A, B). The phase-contrast sequence was obtained in the midsagittal plane, gated with the cardiac cycle using the specific software of GE for this test. Phasic and cine flow images were obtained and studied pre- and postoperatively at 3 months.

Several variables were analyzed including age at presentation, duration of symptoms, main symptomatology, and management. MRI studies were reviewed and the following variables were recorded: presence or absence of cine flow at the craniovertebral junction and diameter of the syrinx cavity.

\section{RESULTS}

The mean age of the patients at presentation was 36 years. Six patients were symptomatic for Chiari type 0 malformation, showing a wide variation as severe suboccipital headache, cervical pain, vertigo, dizziness and motor/sensory deficits (Table I). The mean duration of symptoms was 20 months. Two patients were diagnosed incidentally as a result of MRI performed for other medical reasons. Five patients with Chiari type 0 malformation underwent surgical procedures; suboccipital decompression and duraplasty were performed. Mean clinical follow-up period was 23 months. All 5 patients showed both clinical and radiological improvements in the postoperative period. One month later, postoperative MRI showed mega cisterna manga, but the syrinx cavity showed no change in diameter. Syrinx cavity diameter had decreased at the sixth month after surgery (Figure 2A, B). All patients with Chiari type
0 malformation and absent cine flow preoperatively improved after suboccipital decompression and duraplasty 3 months later (Figures 3,4). One month after surgery, the presenting symptoms of all patients had improved. There was a good correlation between the clinical presentation and the radiological findings in pre- and postoperative periods.

The patients with normal cine flow at the craniovertebral junction in MRI were followed without surgical intervention for approximately two years. Cranial MRI and phase-contrast cine flow MRI were performed at six-months periods. There was progression of clinical and radiological findings or new findings in the follow-up periods.

\section{DISCUSSION}

The Chiari malformations are a group of congenital hindbrain abnormalities which are observed in conjunction with spinal cord malformations. The term "Chiari malformation" has been used to define conditions with ectopia of cerebellar tonsils below the level of the posterior edge of the foramen magnum for several decades. The first published reports were described by Hans Chiari in 1891 (7). They are categorized into four traditional types, with Types I and II accounting for almost $99 \%$ of the clinical cases. Chiari I malformation is characterized by underdevelopment and overcrowding of the posterior cranial fossa and the associated neurological dysfunction secondary to hindbrain compression and syringomyelia. Caudal herniation of cerebellar tonsils more than $5 \mathrm{~mm}$ below the foramen magnum has been described as "Chiari I malformation". Since the late 1990s, there is increasing evidence that many patients with an overcrowded posterior cranial fossa and typical Chiari malformation type I signs, such as syringomyelia, do not show tonsillar descent; many authors refer to these cases as Chiari malformation type 0 (23-26).
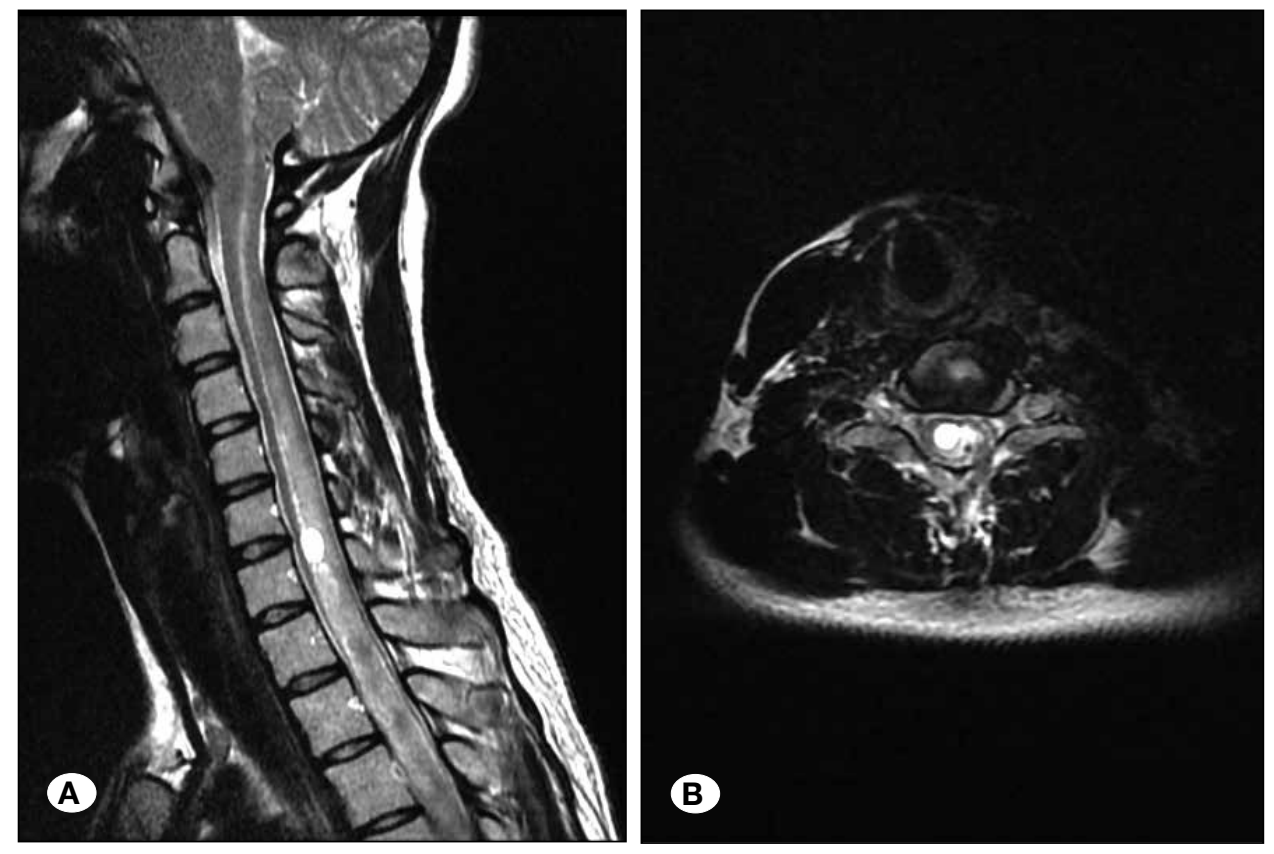

Figure 1: Preoperative A) sagittal and $\mathbf{B}$ ) axial cervical MRI revealing cervicothoracic syringomyelia without tonsillar herniation (Chiari type 0 malformation) (syrinx diameter is $9 \mathrm{~mm}$ ). 
Iskandar et al. first described 5 patients with syringomyelia and no evidence of tonsillar herniation (14). MRI of the entire neuroaxis ruled out other causes of a syrinx. Ultimately, abnormal CSF flow at the posterior fossa or foramen magnum may be a possible cause of syrinx. All five patients underwent a posterior fossa decompression and duraplasty without di- rect fenestration or management of the syrinx. Significant syrinx resolution and symptom improvement were observed in all patients. Their improvements after surgery suggest that "Chiari-like" pathophysiology may be present in the absence of tonsillar herniation, which may possibly be intermittent. This contention is supported by the identification of crowded

Table I: Chiari 0 Patients' Data and Preoperative and Postoperative Radiological Findings

\begin{tabular}{|c|c|c|c|c|c|c|}
\hline Patient & $\begin{array}{c}\text { Age } \\
\text { (years)/ } \\
\text { Sex }\end{array}$ & Symptoms & $\begin{array}{l}\text { Phase-contrast } \\
\text { cine MRI }\end{array}$ & Management & $\begin{array}{c}\text { Preoperative } \\
\text { syrinx } \\
\text { diameter }\end{array}$ & $\begin{array}{c}\text { Postoperative/ } \\
\text { Follow-up syrinx } \\
\text { diameter ( } 6^{\text {th }} \text { month) }\end{array}$ \\
\hline 1 & $30 / F$ & Asymptomatic & Positive cine flow & Follow-up & $4 \mathrm{~mm}$ & $4 \mathrm{~mm}$ \\
\hline 2 & $40 / F$ & Neck pain & Positive cine flow & Follow-up & $8 \mathrm{~mm}$ & $8 \mathrm{~mm}$ \\
\hline 3 & $35 / F$ & Quadriparesis & Absent cine flow & $\begin{array}{c}\text { Suboccipital } \\
\text { decompression and } \\
\text { duraplasty }\end{array}$ & $13 \mathrm{~mm}$ & $7 \mathrm{~mm}$ \\
\hline 4 & $36 / \mathrm{M}$ & $\begin{array}{c}\text { Numbness and pain } \\
\text { in the arms }\end{array}$ & Absent cine flow & $\begin{array}{c}\text { Suboccipital } \\
\text { decompression and } \\
\text { duraplasty }\end{array}$ & $7 \mathrm{~mm}$ & $3 \mathrm{~mm}$ \\
\hline 5 & $32 / \mathrm{M}$ & $\begin{array}{l}\text { Neck pain, headache } \\
\text { and vertigo }\end{array}$ & Absent cine flow & $\begin{array}{c}\text { Suboccipital } \\
\text { decompression and } \\
\text { duraplasty }\end{array}$ & $9 \mathrm{~mm}$ & $3 \mathrm{~mm}$ \\
\hline 6 & $33 / F$ & $\begin{array}{l}\text { Neck pain and } \\
\text { quadriparesis }\end{array}$ & Absent cine flow & $\begin{array}{c}\text { Suboccipital } \\
\text { decompression and } \\
\text { duraplasty }\end{array}$ & $8 \mathrm{~mm}$ & $4 \mathrm{~mm}$ \\
\hline 7 & $43 / F$ & $\begin{array}{l}\text { Neck pain, numbness } \\
\text { and pain in the arms }\end{array}$ & Absent cine flow & $\begin{array}{c}\text { Suboccipital } \\
\text { decompression and } \\
\text { duraplasty }\end{array}$ & $9 \mathrm{~mm}$ & $4 \mathrm{~mm}$ \\
\hline
\end{tabular}

M: Male, F: Female, MRI: Magnetic resonance imaging.

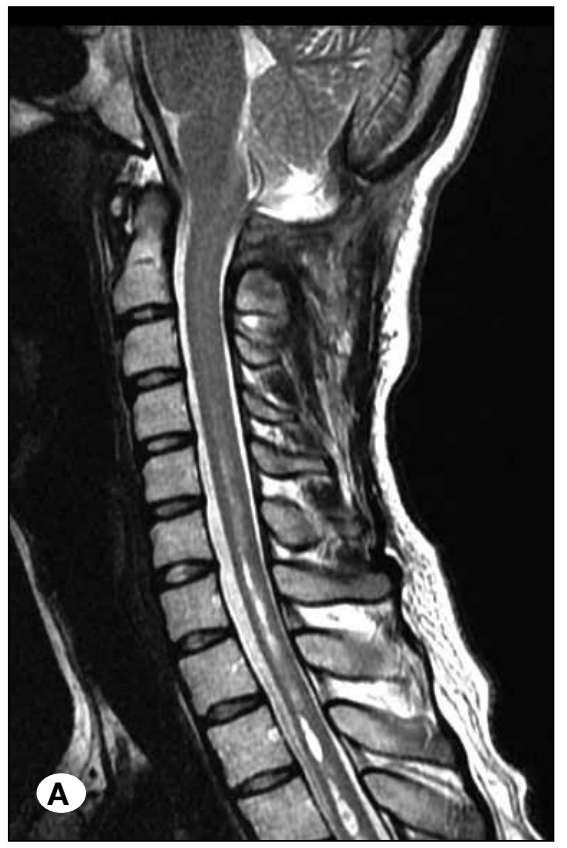

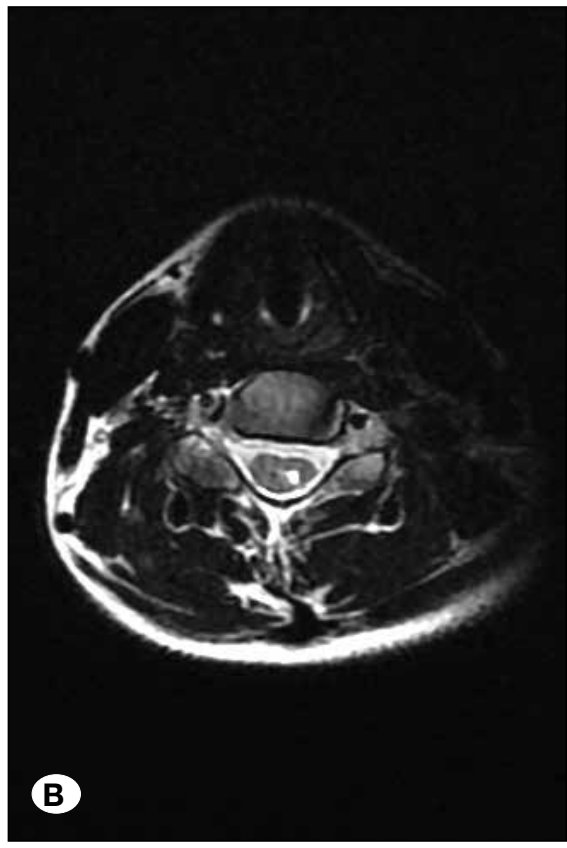

Figure 2: Postoperative A) sagittal and B) axial cervical MRI of the same patient revealing the regression of syringomyelia (postoperative syrinx diameter is $4 \mathrm{~mm}$ ). 


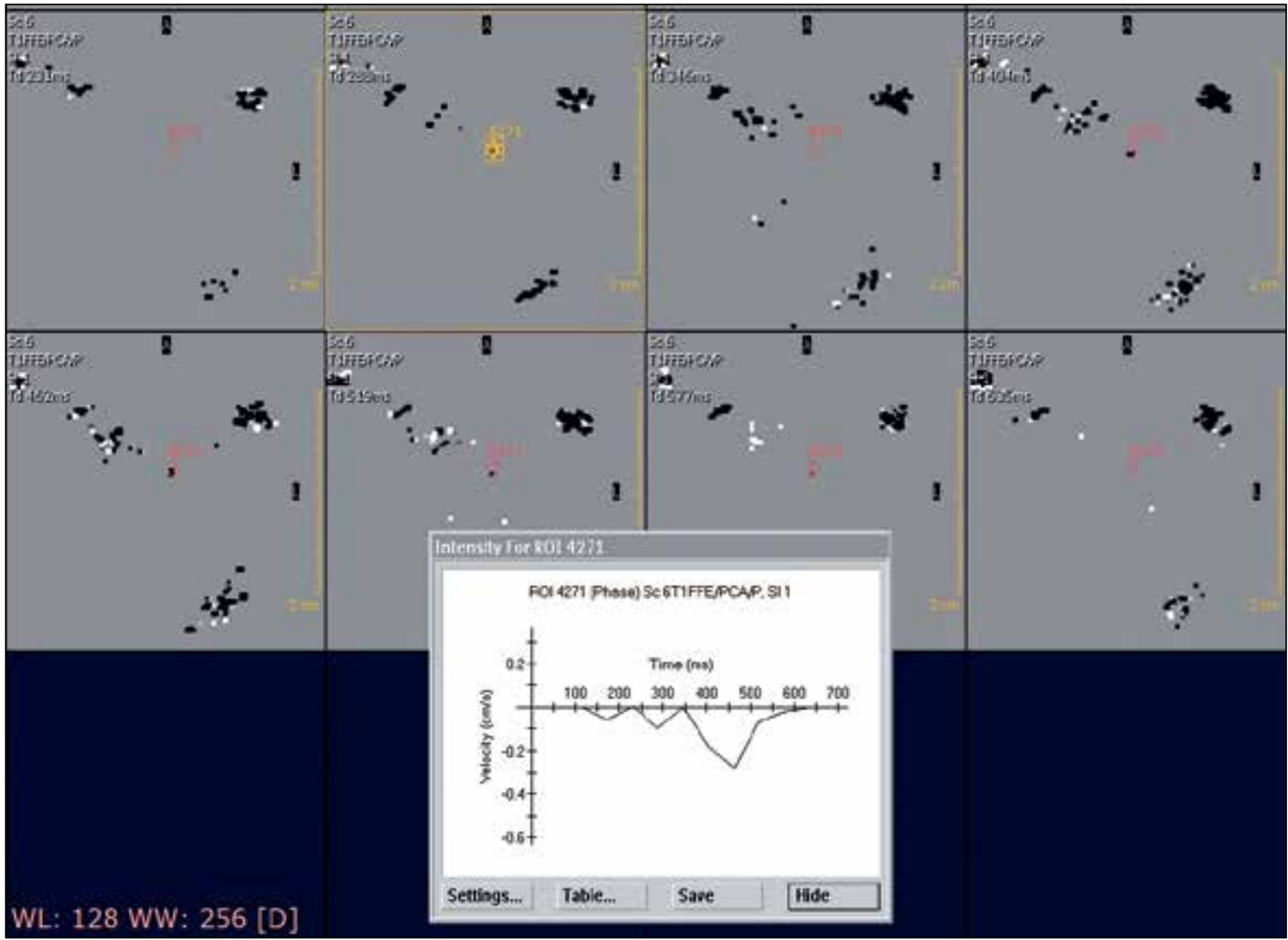

Figure 3:

Preoperative CSF velocity-time graph obtained at the foramen magnum level demonstrates absence of flow.

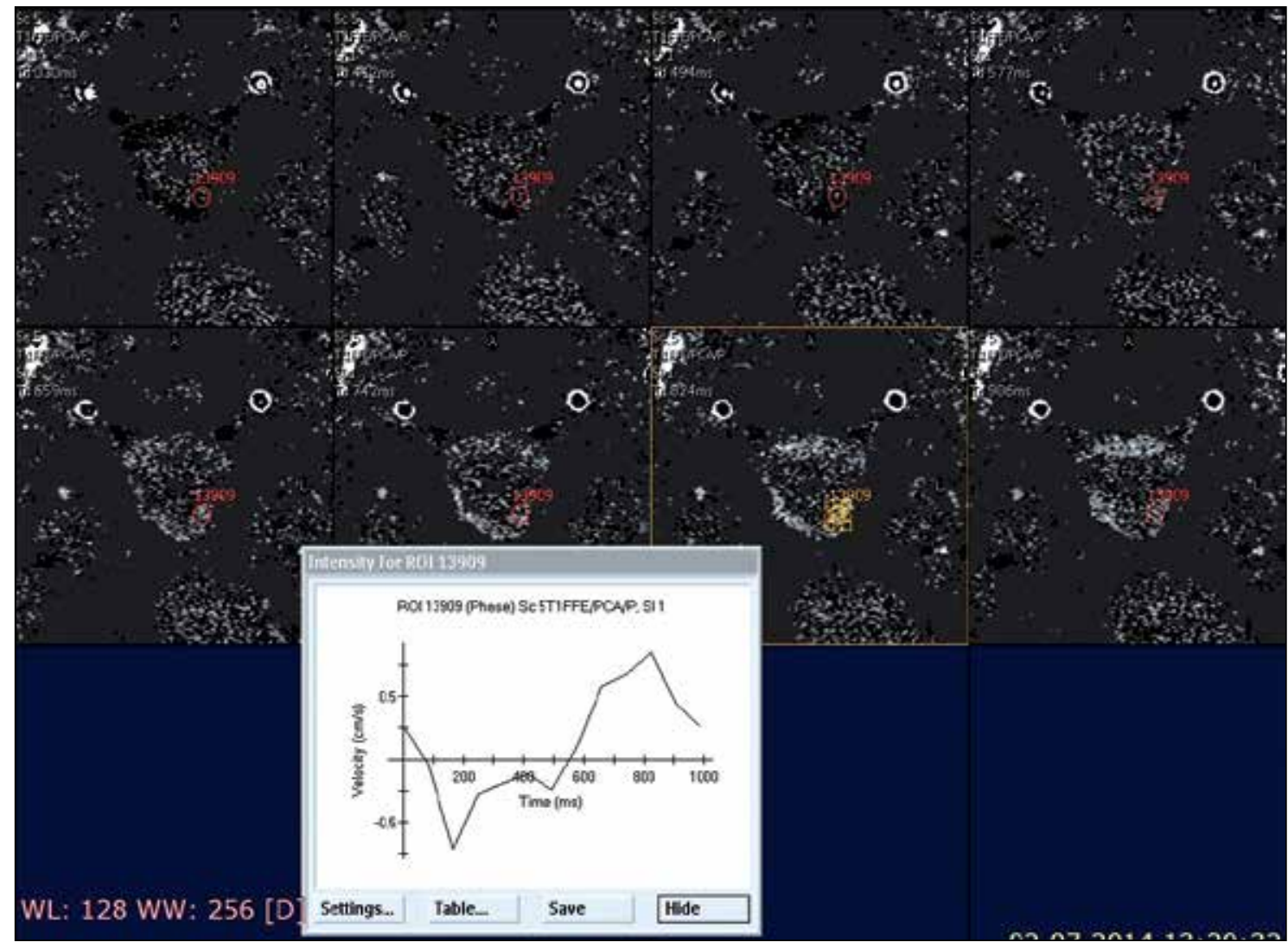

Figure 4:

Postoperative graph of the same patient at the same level demonstrates normal sinusoidal flow pattern. 
foramen magnum in two patients, multiple arachnoid adhesions in two others, and a fourth ventricular arachnoid veil in one. Each of these findings can alter CSF flow, although the pathophysiology resulting in syrinx formation in this group of patients is poorly understood (25).

MRI is an excellent non-invasive method of appreciating the anatomy of this malformation and the associated anomalies, not only as part of the preoperative work-up, but also in the follow-up of surgically treated patients. The incidence of Chiari 0 malformation has increased dramatically over the last decade. This finding is attributed mainly to the widespread use of MRI in clinical practice. Chiari type 0 malformation is also diagnosed incidentally as a result of MRIs performed for other reasons as in our 2 cases.

On MRI, posterior fossa volume tends to be smaller in Chiari malformation when compared with normal individuals, even though this is not always the case (26). Morphometric studies in Chiari malformation patients collaborated the overcrowding of a normally developed hindbrain within a hypoplastic posterior cranial fossa (26). Nishikawa et al. suggested calculating the "volume ratio," defined as brain volume divided by the cranial volume of posterior fossa (evaluated by means of MRI and computed tomography respectively) (19). Nishikawa et al. also reported that posterior fossa volume is smaller in the Chiari malformation (19).

The clinical manifestations of all types of Chiari malformations are classically attributed to the crowding of the posterior fossa structures at the foramen magnum leading to obliteration of the CSF circulation at the craniovertebral junction (27). Phasecontrast cine flow MRI provides useful additional information on this particular aspect. During the cardiac cycle, there is bi-directional craniospinal displacement of CSF. Greitz et al. demonstrated this pulsatile motion using phase contrast MRI (12). During systole, there is an increase in cerebral blood volume and CSF is displaced caudally through the foramen magnum as a compensatory mechanism. During diastole, the elastic recoil of the spinal dura mater propels the CSF in a caudocranial direction towards the intracranial compartment $(4,9,10,16)$. Phase-contrast cine flow MRI studies have demonstrated that Chiari type I malformation can have pathological CSF flow at the level of foramen magnum $(1,5,16,21,22)$. Following posterior fossa decompression, abnormal CSF flow reverts to normal and parallels symptomatic improvement $(1,5,16,21,22)$. In the present study, we first investigated the significance of the abnormal CSF circulation at the craniocervical junction in Chiari type 0 patients for understanding the pathophysiology of syrinx development. Our six cases have an obstruction in cine flow MRI at the craniovertebral junction and this finding improved after suboccipital decompression and duraplasty. There is no literature knowledge about altered CSF dynamics at the craniovertebral junction correlated with clinical symptomatology in patients with Chiari 0 malformation.

The clinical significance of these radiological findings remains questionable for patients who were diagnosed incidentally. In these cases, cine flow MRI studies may be performed to evaluate CSF flow at the craniovertebral junction.
Syringomyelia was demonstrated in $50-70 \%$ of all types of patients with Chiari malformation $(6,17,20,28)$. Their more frequent location is cervical and thoracic levels, even though C1 is almost never affected; in about $20 \%$ of the cases the syrinx extends to the whole spinal cord (6). In our cases, syringomyelia was located at the lower cervical levels.

The management algorithm of Chiari type 0 syndrome is still controversial. There are only few reports in which the authors published their treatment modalities and postoperative results for these patients. We reported 7 cases with Chiari type 0 syndrome and reviewed the literature to determine the differences between the treatment options of Chiari type 0 with syringomyelia.

Patients with Chiari I malformation and associated syringomyelia usually show improvement after suboccipital decompression and duraplasty $(18,27)$. However, these patients do not improve after suboccipital decompression alone $(3,15,18)$. The degree of hindbrain CSF flow obstruction correlated with presenting symptomatology and predicted the response to the surgery. McGirt et al. also reported that normal preoperative hindbrain CSF flow was an independent risk factor for treatment failure after decompression for Chiari type I malformation regardless of the degree of tonsillar ectopia (16). Based on these observations, it seems that augmentation duraplasty contributes significantly to the restoration of CSF flow at the craniovertebral junction $(3,13)$. Therefore, our symptomatic Chiari type 0 patients were treated surgically by posterior fossa decompression and duraplasty. As such, a thorough neuroaxis evaluation is necessary to exclude other causes of syrinx before consideration of posterior fossa decompression (25).

The management of asymptomatic patients that was incidentally found during routine MRI studies may be problematic. In this case, cine flow MRI studies may be performed to evaluate cine flow at the craniovertebral junction. If cine flow MRI studies are normal, asymptomatic patients would be followed without surgical intervention. This condition may be progressive and it is recommended that patients with Chiari 0 malformations found incidentally should undergo careful clinical and radiological follow-up as in our cases. Despite these encouraging outcomes, the number of cases in this study is not large enough to draw a solid conclusion.

Resolution of clinical symptoms after hindbrain decompression in patients with Chiari malformation associated syrinx ranges from $35 \%$ to $100 \%$ in different series $(2,8,11)$. In fact, apart from clinical improvement, the success of posterior fossa decompression should be integrated by neuroimaging studies. The reduction in size of a syrinx in MRI can be utilized as an objective neuroradiological sign of improvement. McGirt et al. reported that marked reduction and resolution of syringomyelia in $65 \%$ of patients who were followed by MRI (16). Stabilization in syrinx size was observed in the remaining $35 \%$ of patients. Many patients with symptomatic Chiari type I malformation presented with recurrent symptoms after surgical decompression alone. In these cases, McGirt et al. reported that phase-contrast cine flow MRI may be a valuable tool (16). Phase-contrast cine flow MRI can identify patients 
who are less likely to respond to surgical decompression. Our symptomatic Chiari type 0 patients with abnormal cine flow MRI studies showed both clinical and radiological improvements after surgical intervention. Complete preoperative CSF flow obstruction predicted long-term resolution of symptoms.

\section{CONCLUSION}

Cine flow MRI appears to be helpful in the diagnosis and management of patients with Chiari 0 malformations. CSF flow turns to normal ranges after surgical treatment, which correlated radiologically with syrinx resolution or reduction, and symptomatic improvement.

\section{- REFERENCES}

1. Armonda RA, Citrin CM, Foley KT, Ellenbogen RG: Quantitative cine-mode magnetic resonans imaging of chiari I malformations; An analysis of cerebrospinal fluid dynamics. Neurosurgery 35: 214-223, 1994

2. Attenello FJ, McGirt MJ, Gathinji M, Datoo G, Atiba A, Weingart J, Carson B, Jallo Gl: Outcome of Chiari- associated syringomyelia after hindbrain decompression in children: Analysis of 49 consecutive cases. Neurosurgery 62: 13071312, 2008

3. Badie B, Mendoza D, Batzdorf U: Posterior fossa volume and response to suboccipital decompression in patients with Chiari I malformation. Neurosurgery 37: 214-224, 1995

4. Bhadelia RA, Bogdan AR, Wolpert SM: Analysis of cerebrospinal fluid flow waveforms with gated phase-contrast MR velocity measurement. Am J Neuroradiol 16: 389-400, 1995

5. Bhadelia RA, Bogdan AR, Wolpert SM, Lev S, Appignani BA, Heilman CB: Cerebrospinal fluid flow waveforms: Analysis in patients with Chiari I malformations by means of gated phasecontrast MR imaging velocity measurements. Radiology 196: 195-202, 1995

6. Caldarelli M, Di Rocco C: Diagnosis of Chiari I malformation and related syringomyelia: Radiological and neurophysiological studies. Childs Nerv Syst 20: 332-335, 2004

7. Chiari $\mathrm{H}$ : Uber Veranderungen des Kleinhirns infolge von Hydrocephalie des Grosshirns. Dtsch Med Wochenshr 17: 1172-1175, 1891

8. Depreitere B, Van Calenbergh F, van Loon J, Goffin J, Plets C: Posterior fossa decompression in syringomyelia associated with a Chiari malformation: A retrospective analysis of 22 patients. Clin Neurol Neurosurg 102: 91-96, 2000

9. Enzmann DR, Pelc NJ: Normal flow patterns of intracranial and spinal cerebrospinal fluid defined with phase-contrast cine MR. Imaging Radiology 178: 467-474, 1991

10. Enzmann DR, Pelc NJ: Cerebrospinal fluid flow measured by phase-contrast cine MR. Am J Neuroradiol 14: 1301-1307, 1993

11. Feldstein NA, Choudhri TF: Management of Chiari I malformations with holocord syringohydromyelia. Pediatric Neurosurg 31: 143-149, 1999

12. Greitz D, Wirestam R, Frank A, Nordell B, Thomsen C, Stahlberg F: Pulsatile brain movement and associated hydrodynamics studied by magnetic resonance phase imaging. Neuroradiology 34: 370-380, 1992
13. Hida K, Iwasaki Y,Koyanagi I, Sawamura Y, Abe H: Surgical indication and results of foramen magnum decompression versus syringo-subarachnoid shunting for syringomyelia associated with Chiari I malformation. Neurosurgery 37: 673679, 1995

14. Iskandar BJ, Hedlund GL, Grabb PA, Oakes WJ: The resolution of syringohydromyelia without hindbrain herniation after posterior fossa decompression. J Neurosurg 89(2): 212216, 1998

15. McGirt MJ, Nimjee SM, Floyd J, Bulsara KR, George TM: Correlation of cerebrospinal fluid flow dynamics and headache in Chiari 1 malformation. Neurosurgery 56: 716-721, 2005

16. McGirt MJ, Nimjee SM, Fuchs HE, George TM: Relationship of CINE phase contrast MRI to outcome after decompression for Chiari I malformation. Neurosurgery 58: 140-146, 2006

17. Menezes AH: Chiari I malformations and hydromyeliacomplications. Pediatr Neurosrg 17: 146-154, 1991

18. Munshi I, Frim D, Stine-Reyes R,Weir BK, Hekmatpanah J, Brown F: Effects of posterior fossa decompression with and without duroplasty on Chiari malformation associated hydromyelia. Neurosurgery 46: 1384-1390, 2000

19. Nishikawa M, Sakamoto $H$, Hakuba A, Nakanishi N, Inoue $Y$ : Pathogenesis of Chiari malformation: A morphometric study of the posterior cranial fossa. J Neurosurg 86: 40-47, 1997

20. Oakes WJ: The Chiari malformations of the child. In: Menezes $\mathrm{AH}$, Sonntag VKH (ed), Principals of Spinal Surgery. New York: McGraw-Hill, 1996: 379-394

21. Oldfield EH, Muraszko K, Shawker TH, Patronas NJ: Pathophysiology of syringomyelia associated with Chiari I Malformations of the cerebellar tonsils. Implications for diagnosis and treatment. Neurosurg 80: 3-15, 1994

22. Panigrahi M, Reddy BP, Reddy AK, Reddy JJM: CSF flow study in Chiari I malformation. Childs Nerv Syst 20: 336-340, 2004

23. Sekula RF Jr, Janetta PJ, Casey KF, Marchan EM, Sekula LK, Mccrady CS: Dimensions of the posterior fossa in patients with symtomatic for Chiari I malformation but without cerebellar tonsillar descent. Cerebrospinal Fluid Res 2: 11, 2005

24. Tubbs RS, Elton S, Grabb P, Dockery SE, Bartolucci AA, Oakes WJ: Analysis of posterior fossa in children with Chiari 0 malformation. Neurosurgery 48(5): 1050-1054, 2001

25. Tubb RS, Pugh JA, Oakes WJ: Chiari Malformations. In: Winn HR (ed), Youmans Neurological Surgery. Philadelphia: Elsevier Saunders, 2011: 1918-1927

26. Urbizu A, Poca MA, Vidal X, Rovira A, Sahuquillo J: MRIbased morphometric analysis of posterior cranial fossa in the diagnosis of Chiari malformation type I. J Neuroimaging 1: 7, 2012

27. Ventureyra ECG, Aziz HA, Vassilyadi M: The role of cine flow $\mathrm{MRI}$ in children with Chiari I malformation. Childs Nerv Syst 19: 109-113, 2003

28. Wu YW, Chin CT, Chan KM, Barkovich AJ, Ferriero DM: Pediatric chiari I malformations: Do clinical and radiological features correlate? Neurology 53: 1271-1276, 1999 